\title{
Anatomical variants of coeliac trunk in Polish population using multidetector computed tomography angiography
}

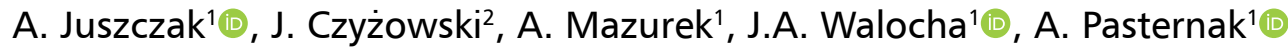 \\ ${ }^{1}$ Department of Anatomy, Jagiellonian University Medical College, Krakow, Poland \\ 2Institute of Diagnostic Imaging, J. Diet/ Specialist Hospital, Krakow, Poland
}

[Received: 19 March 2020; Accepted: 14 April 2020]

Background: Multidetector computed tomography angiography (MDCTA) has become a major part in evaluation of normal anatomy and its variants in patients undergoing operative or interventional procedures. The purpose of this study was to assess the frequency of anatomical variation of coeliac trunk in patients undergoing MDCTA of the abdominal aorta.

Materials and methods: A descriptive, retrospective study was carried out on MDCTAs performed from January 2014 till January 2020 in Polish patients. Coeliac trunk was studied and normal and anatomical variations were noted according to Adachi's classification. All patients with abnormalities affecting the vessels or a history of any vascular abnormality were excluded from the study.

Results: Out of total 1000 patients, hepatogastrosplenic trunk was found in 93.0\%. True and false types of trifurcation were observed. Hepatosplenic trunk was found in $2.8 \%$, coeliacomesenteric trunk in $1.1 \%$, hepatomesenteric trunk in $1.7 \%$ gastrosplenic trunk was found in $1.4 \%$. We have not observed hepatosplenomesenteric trunk.

Conclusions: The type and knowledge of anatomy is of prime importance for an optimum preoperative planning in surgical or radiological procedure. MDCTA allows minimally invasive assessment of arterial anatomy with high quality three-dimensional reconstruction images. (Folia Morphol 2021; 80, 2: 290-296)

Key words: celiac trunk, variations, multidetector computed tomography angiography

\section{INTRODUCTION}

The most common classical type of coeliac trunk branching pattern is referred to as trifurcation (Fig. 1A, B) and was first observed by von Haller [37], i.e. tripus Halleri. It has been considered to be the normal appearance of computed tomography (CT). According to Haller, coeliac trunk divides into common hepatic artery $(\mathrm{CHA})$, splenic artery $(\mathrm{SA})$ and left gastric artery
(LGA), which usually arises as a tributary elsewhere in this trunk, while the other divisions of coeliac trunk rarely occur in human populations. The anatomical variations of coeliac trunk were classified for the first time by Adachi in 1928 [1]. Investigations were performed on 252 people of Japanese origin and these formed the basis of Adachi's classification of the 6 types of division of coeliac trunk and superior mesen-

Address for correspondence: A. Pasternak, MD, PhD, Department of Anatomy, Jagiellonian University Medical College, ul. Kopernika 12, 31-034 Kraków, Poland, tel: +48 1242295 11, fax: +48 1242295 11, e-mail: artur.pasternak@uj.edu.pl

This article is available in open access under Creative Common Attribution-Non-Commercial-No Derivatives 4.0 International (CC BY-NC-ND 4.0) license, allowing to download articles and share them with others as long as they credit the authors and the publisher, but without permission to change them in any way or use them commercially. 


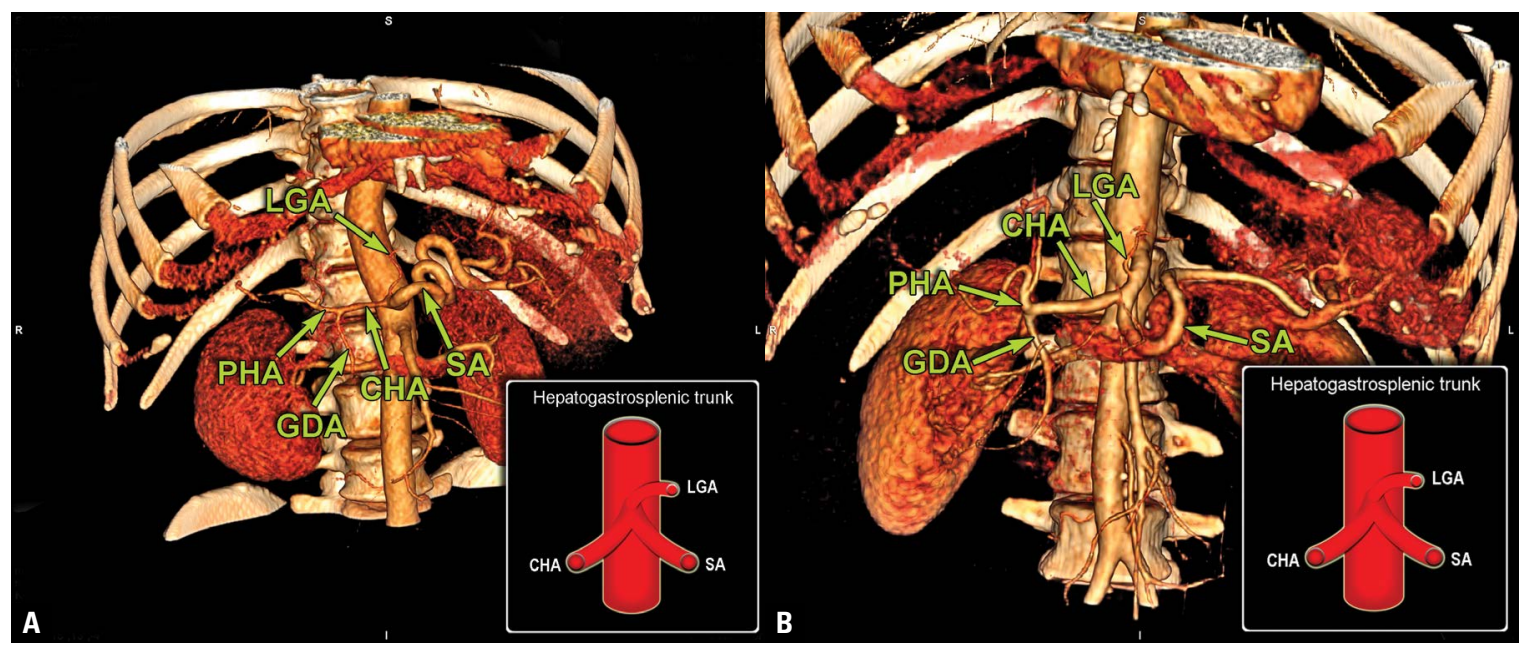

Figure 1. A. True tripod; B. False tripod; CHA — common hepatic artery; GDA — gastroduodenal artery; LGA — left gastric artery; PHA — proper hepatic artery; SA — splenic artery.

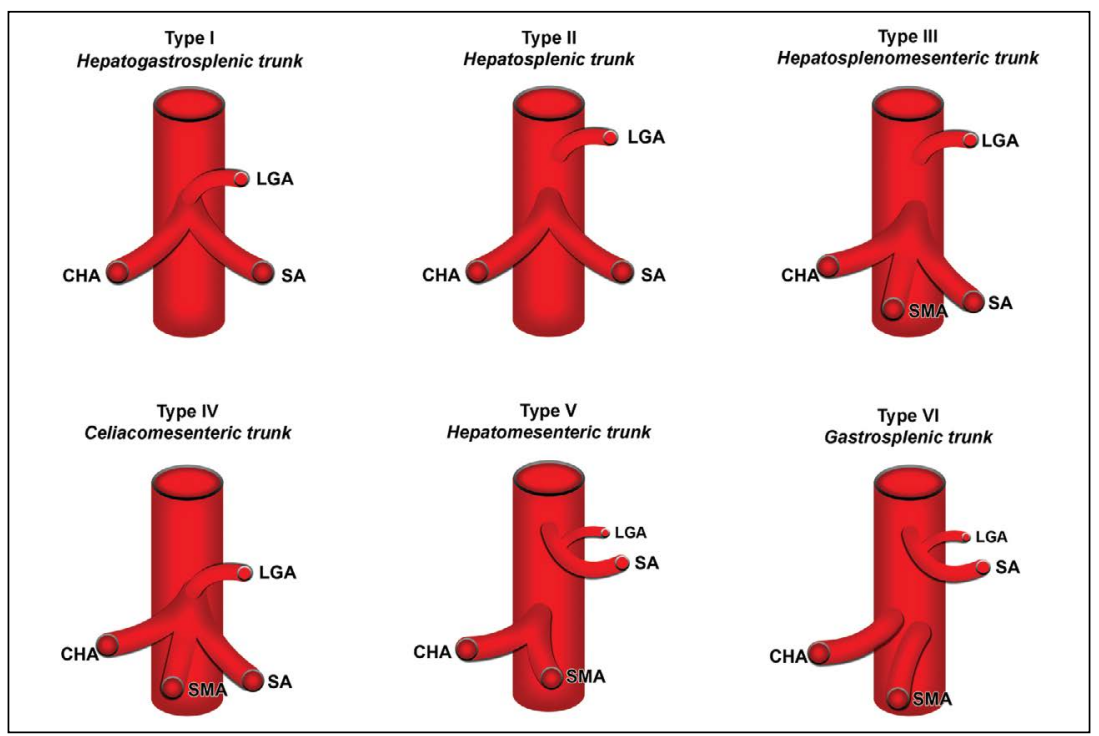

Figure 2. Coeliac trunk trifurcation types according to Adachi; CHA — common hepatic artery; LGA — left gastric artery; SA — splenic artery; SMA — superior mesenteric.

Table 1. Adachi's classification of coeliac trunk variations

\begin{tabular}{lcc}
\hline Trunk classification & $\begin{array}{c}\text { Trunk classification } \\
\text { number }\end{array}$ & Percentage \\
\hline Hepatogastrosplenic & 1 & $86 \%$ \\
Hepatosplenic & 2 & $8 \%$ \\
Gastrosplenic & 6 & $3 \%$ \\
Coeliacomesenteric & 4 & $1.5 \%$ \\
Hepatosplenomesenteric & 3 & $1 \%$ \\
Hepatomesenteric & 5 & $0.5 \%$ \\
\hline
\end{tabular}

teric artery (SMA) (Fig. 2, Table 1). Knowledge of coeliac trunk branching pattern is mandatory in laparoscopic surgery, liver transplants, radiological abdominal in- terventions and penetrating abdominal injuries [42]. Lack of familiarity with such variants can result in insufficient management and predispose patients to inadvertent injury during open surgical procedures or percutaneous interventions. In recent 20 years, with the widespread use of multidetector computed tomography and angiography (MDCTA), it is easy to collect a large sampling of data on the angiographic anatomy of the abdomen in daily radiological practice. Then, the variation patterns and radiological findings of coeliac trunk can be classified and evaluated in detail by MDCTA. The main purpose of this study was to evaluate the frequency of normal and anatomical variations of coeliac trunk in Polish patients undergoing MDCTA of 
the abdominal aorta for various clinical indications. The use of MDCTA allowed for identification of its types and prevalence in a large study population. We also discussed their clinical implications and the probable embryological mechanisms by which the observed variations are achieved. It has become significant to be aware of the normal variations in the vascular supply of these organs, in order to prevent complications during and after surgery.

\section{MATERIALS AND METHODS}

This study was conducted at the Institute of Diagnostic Imaging, J. Dietl Specialist Hospital in Krakow, Poland. One thousand patients referred to CT angiogram of abdominal aorta for various reasons irrespective of age and gender were included in this study. All the patients underwent abdominal MDCTA in Aquilion 64, Toshiba Medical Systems Corporation, Tokyo, Japan. Local Institutional Ethical Committee approval was obtained. Being a retrospective study, informed consent was not obtained as the data was collected retrospectively from the electronic medical record database. Abdominal CT angiographic images from 01.2014 till 01.2020 were studied for coeliac trunk anatomical variation. The pattern of the aortic origin of branches of coeliac trunk and its branches was analysed.

Multiphase enhanced MDCT scan was performed after intravenous administration of contrast agent (Omnipaque 350; GE Healthcare AS, Oslo, Norway) at $350 \mathrm{mg}$ of iodine per millilitre and $30 \mathrm{~mL}$ of sterile saline $(0.9 \% \mathrm{NaCl})$ by using a power injector at a rate of 3-4 mL/s. The dose of the contrast agent was $1 \mathrm{~mL} / \mathrm{kg}$ body weight and the upper limit of dose was set at $100 \mathrm{~mL}$ for every patient. Data obtained during the arterial phase were used to evaluate the anatomy of the coeliac trunk. The raw axial images obtained from MDCT were processed on the workstation to obtain three-dimensional (3D) reconstruction with maximum intensity projection (MIP) and volume rendering (VR). The analysis of the images was carried out by an experienced radiologist.

Identification of coeliac trunk and its branches was possible in all patients examined. Patients with distorted anatomy due to previous abdominal surgery, degenerative spine conditions or any abnormality that involved the vessels were excluded. The pattern of the aortic origin of the four major arteries: left gastric, the common hepatic, splenic and superior mesenteric arteries were analysed in the study. The instructional 3D models of the coeliac trunk and its abnormalities were designed. Anatomical variations of the coeliac trunk were reported according to Adachi's classification (Table 1). Coeliac trunk was also assessed for its diameter, distance from the SMA, angle of departure from the abdominal aorta and projection on the spine.

\section{Statistical analysis}

Statistical package for social sciences (SPSS) version 21 was used for statistical analysis. Mean and standard deviation was calculated for age of the patients. Frequency and percentages was calculated for normal anatomy and anatomical variations of coeliac trunk. Comparison was done to see the relationship among coeliac artery variant. Chi-square test was applied. P-value was taken as $<0.05$.

\section{RESULTS}

Out of total 1000 patients, 510 (51\%) were males and 490 (49\%) were females. The mean age of the patients was $65.2 \pm 19.75$ years. According to Adachi's first classification, there are 6 branching types of the coeliac trunk: hepatogastrosplenic, hepatosplenic, hepatosplenomesenteric, hepatomesenteric, gastrosplenic, coeliacomesenteric. Hepatogastrosplenic trunk (type I according to Adachi's classification) dividing into 3 branches i.e. LGA, CHA and SA was found in $93.0 \%$ (930/1000). Two different types of this trifurcation were observed: (a) a true tripod when the coeliac trunk ended in a complete trifurcation ( $\approx 35 \%$, $325 / 930$ ) and (b) a false tripod when the three arteries did not have a common origin ( $\approx 65 \%, 605 / 930)$ (Fig. 1A, B). Type II (i.e. hepatosplenic trunk) was found in $2.8 \%(28 / 1000)$ (Fig. 3). Type IV (i.e. coeliacomesenteric trunk) was found in $1.1 \%(11 / 1000)$ (Fig. 4), type $\mathrm{V}$ (i.e. hepatomesenteric trunk) was found in 1.7\% (17/1000) (Fig. 5), type VI (i.e. gastrosplenic trunk) was found in 1.4\% (14/1000) (Fig. 6). We have not observed type III (i.e. hepatosplenomesenteric trunk). The level of coeliac trunk origin was found to be at the inter-vertebral disc between T12 and L1 in all of the cases. The angle of departure of the coeliac trunk from the abdominal aorta varied widely from $6.8^{\circ}$ to $85.6^{\circ}$ (Table 2 ).

On average, the coeliac trunk calibre was $11.7 \mathrm{~mm}$, with the largest one of $18.1 \mathrm{~mm}$ and the smallest of $5.3 \mathrm{~mm}$, and standard deviation of 0.13 . The mean distance between the coeliac trunk and the SMA was $15 \mathrm{~mm}$, the largest - $22 \mathrm{~mm}$, and the shortest $3 \mathrm{~mm}$, with standard deviation of 0.4 . 


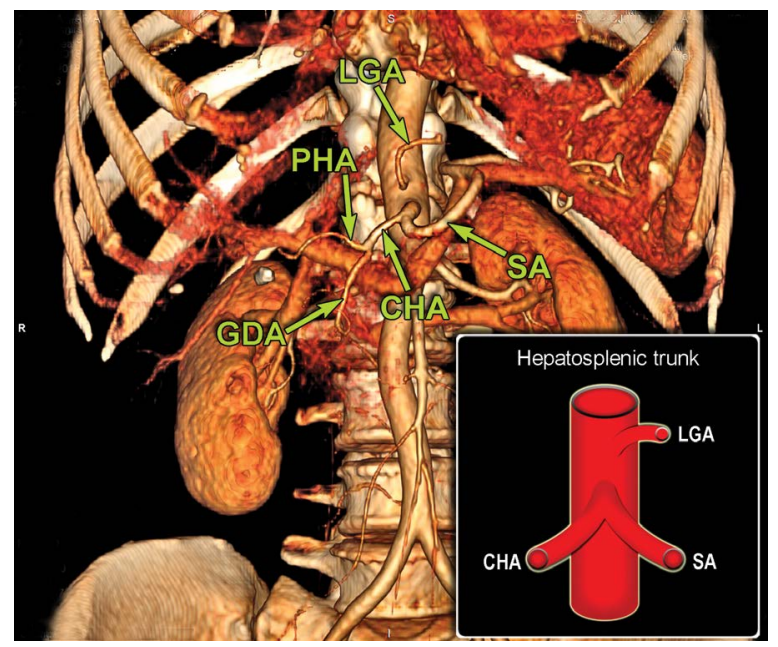

Figure 3. Hepatosplenic trunk; abbreviations - see Figure 1.

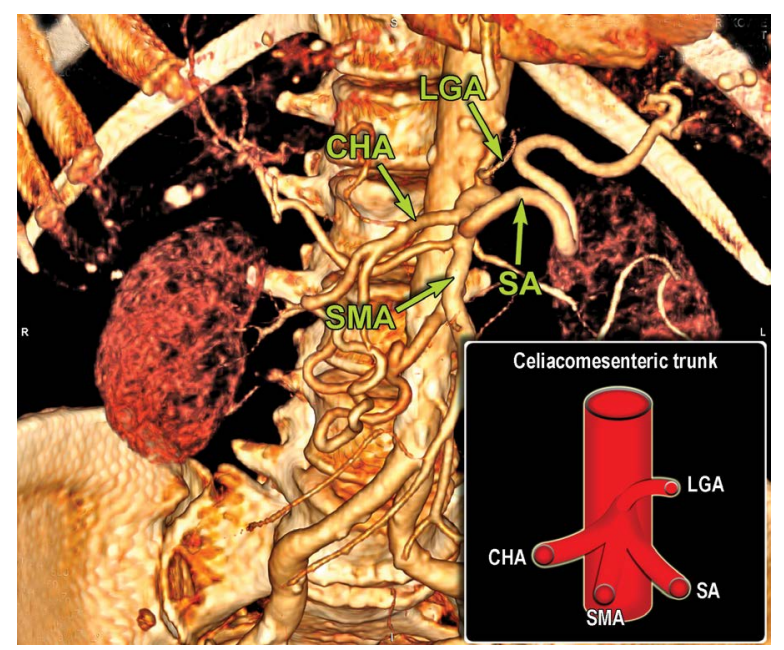

Figure 4. Coeliacomesenteric trunk; abbreviations — see Figure 1.

Table 2. Coeliac trunk variations according to Adachi's classification found in the study

\begin{tabular}{lcc}
\hline Trunk classification & $\begin{array}{c}\text { Trunk classification } \\
\text { number }\end{array}$ & Percentage \\
\hline Hepatogastrosplenic & 1 & $93 \%$ \\
Hepatosplenic & 2 & $2.8 \%$ \\
Gastrosplenic & 6 & $1.4 \%$ \\
Coeliacomesenteric & 4 & $1.1 \%$ \\
Hepatosplenomesenteric & 3 & $0 \%$ \\
Hepatomesenteric & 5 & $1.7 \%$ \\
\hline
\end{tabular}

\section{DISCUSSION}

Anatomic variations of the coeliac trunk and SMA occur due to anomalous embryogenesis of primitive ventral blood vessels originating from the abdominal

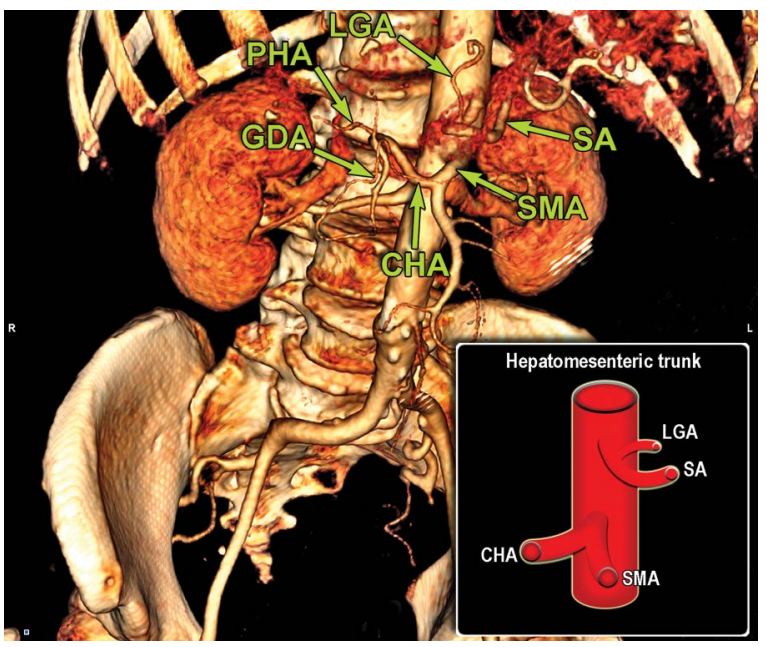

Figure 5. Hepatomesenteric trunk; abbreviations — see Figure 1.

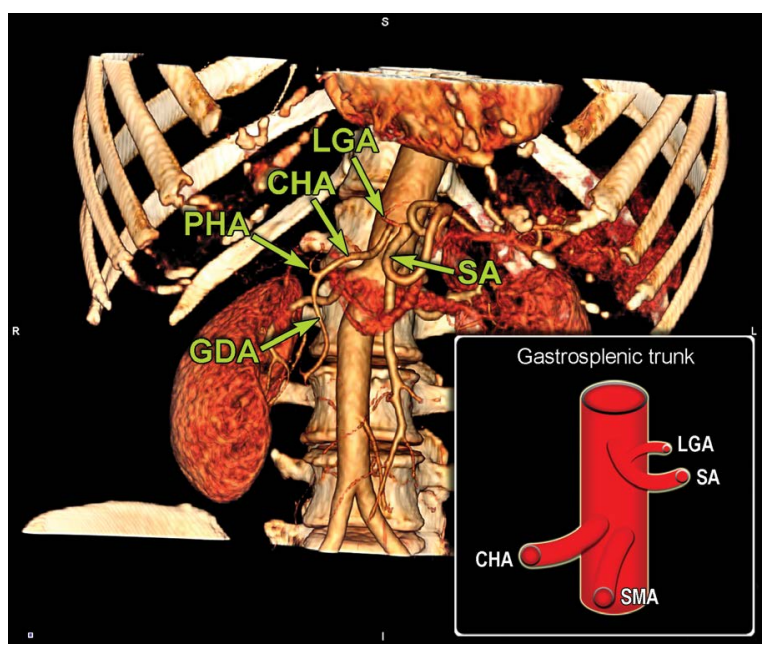

Figure 6. Gastrosplenic trunk; abbreviations — see Figure 1.

aorta [33]. In our study, there were 4 types of coeliac axis variation identified in 70 patients, with normal coeliac axis anatomy in 930 (93\%) patients as compared with $89 \%$ in the dissection study conducted by Michels [25]; $91 \%$ in the study conducted by Sureka et al. [31]; $86 \%$ in the study conducted by Sankar et al. [29]; 85.1\%, 89.5\%, and 95.4\%, respectively, in cadaver studies, imaging studies, and liver transplantation studies, as reported by Panagouli et al. [27]; $89.1 \%$ in the study conducted by Song et al. [30]; $89.8 \%$ in the study conducted by Chen et al. [8], who analysed a population defined as homogeneous in Japan; and $90 \%$ in the study conducted by Araujo-Neto et al. [2]. The hepatosplenic trunk (2.8\%) was the most common coeliac artery variation with separate origin of LGA and SMA followed by coeliacomesenteric trunk (1.1\%). Gastrosplenic trunk with separate origin of 
SMA and CHA from aorta was not found in our study which was found in $0.22 \%$ and $0.83 \%$ in the studies of Song et al. [30] and Sureka et al. [31], respectively.

Multidetector computed tomography angiography has become a valuable tool for the visualisation of normal vascular anatomy and its variants. Furthermore, reformatted 3D MDCT images allow visualisation of vascular structures in angiography equivalent planes other than the axial, which is useful for evaluation of complex vascular anatomy $[3,14]$. Rapid volumetric acquisition of thin-slice high resolution images of the abdominal arteries during the phase of maximal contrast enhancement with the help of MDCT allows $3 \mathrm{D}$ reconstructions to be created, providing the radiologist and the surgeon with a 3D model of the patient's arterial anatomy. MDCT angiography has a reported accuracy of $97-98 \%$ compared with conventional angiography for detecting arterial variants [41]. The disadvantages include potential for contrast reactions, nephrotoxicity, and exposure to ionizing radiation.

Knowledge about the spectrum of coeliac trunk variations is important for planning surgical or interventional procedures in the upper abdomen. Identification of coeliac trunk variations may avoid vascular complications during medical procedures, such as hepatobiliary surgery, pancreatic surgery, gastrectomy and others like transcatheter arterial chemoembolisation [10, 13, 24, 34, 40].

Many endovascular procedures require detailed acquaintance regarding specific features of the particular blood vessels. It is especially noticeable in planning embolisation both as intervention to control haemorrhage and as bariatric procedure. Haemorrhages can occur in the course of many vascular and non-vascular pathologies such as ruptured aneurysms, pseudocysts (due to pancreatitis which commonly lead to erosion of the splenic artery $[4,16]$ ) or posttraumatic injuries (very often due to splenic injuries [9]) and inflammatory diseases. i.e. pancreatitis with related bleeding [19]. In most of the mentioned cases the procedure is done within splenic artery or its branches $[9,19]$ and it is crucial to be acquainted with variations of the course of this artery, especially when the surgeon is planning the proximal splenic artery embolisation which is faster instead of the distal, recommended to focal lesions in the spleen [9].

The embolisation is also used in bariatric treatment. Recent studies revealed that the procedure of embolisation the LGA could improve loss of weight, decreases the concentration of ghrelin and HbA1c
$[21,32,39]$, but the veritable efficacy is still investigated [39]. It is important to take into account detailed features of the LGA (s-shape) and its variation of emerging from the coeliac axis and notice that the position of the coeliac trunk might be horizontal, parallel or inferior which could affect manipulation difficulties [21].

One should bear in mind various angles of departure of the coeliac axis from abdominal aorta. In our study angle varied widely from $6.8^{\circ}$ do $85.6^{\circ}$. Besides a hepatectomy, systemic chemotherapy and arterial chemoinfusion therapy are used to treat primary and liver metastatic cancers. Catheter insertion is necessary for arterial infusion chemotherapy, and there are surgical and percutaneous catheter insertion methods. The catheter insertion route is selected depending on the branching angle (upward or downward) of the origin of the coeliac artery in some cases, and assessments of the branching angle before catheter insertion may increase the reliability of the technique. In recent studies Tokue et al. [35] measured the branching angle of the coeliac trunk in 1200 patients aged 19-91 years with hepatocellular carcinoma. Similarly to our results, the branching was downward in most of patients. Prior information of the branching angle before catheter insertion may increase the reliability of the insertion technique and the completion rate of the therapy.

Many recent studies about liver transplantation revealed that the knowledge about the anatomy of the hepatic and aberrant (accessory or replaced) hepatic arteries emerging directly from the coeliac trunk or its branches is significant to prevent complications both at the recipients and the living donors $[6,7,15,17$, $22,38]$. The complications after donation which eventuate from imprecise analysis of hepatic arteries and the other vessels include: sepsis, acute hepatic failure, biliary leaks of stricture or vascular thrombosis [6]. Thus, there is a trend to preserve accessory and replaced hepatic arteries as well as it is possible if there is not insurance about the blood supply in the same area of liver. In some cases this preservation could not be equal at the recipient and the donor so that it is important to analyse meticulously distribution of arteries in both circumstances $[6,7,38]$. According to Michels' classification there are described cases of replaced left hepatic artery (10\%) and accessory left hepatic artery (8\%), both originating from LGA [25]. The appropriate retaining of arteries supplying the donor's left lobe is essential to provide adequate 
regeneration of the rest of liver $[6,7]$. During planning the surgery in some cases there could be difficulties to palpate the accessory hepatic artery branching of the LGA. This could be resolved by finding the LGA which sometimes could not pass from the coeliac axis (for example in the hepatosplenic trunk) [38]. The replaced right hepatic artery frequently originating from the proper hepatic artery (from CHA) but sometimes (11\%) it arises from superior mesenteric artery [25] and it also should be considered in planning the transplant procedure.

The awareness of variations of the coeliac axis is also significant in treatment for patients with diagnosed hepatocellular carcinoma and the other primary hepatic cancers. Roma et al. [28] revealed that the right inferior phrenic artery - one of the branches of the abdominal aorta or the coeliac trunk (which is the second most common origin $[5,20])$ is the part of the collateral circulation and supplies the liver cancer in the most cases. This fact has an impact on planning treatment of the peripheral lesions such as the chemoembolisation procedure [28]. Maki et al. [22] mentioned that this artery and the other ones (left inferior phrenic, gastric, internal mammary arteries and omental arteries) creating the collateral circulation of the liver should be preserved to avoid postoperative alanine aminotransferase elevation due to hepatic ischaemia.

Considering the other oncological issues: gastric, oesophageal and pancreatic cancer, the procedure of resection of the neoplasms very often includes lymphadenectomy of the lymph nodes surrounding the coeliac axis, LGA or the CHA and SA $[6,12,26]$. The variations of the coeliac trunk and its branches could restrict surgeon's manipulations during dissecting lymph nodes and lead to prolonged operative time and increased risk of iatrogenic complications $[6,26]$. It is also crucial to analyse thoroughly the anatomy of the blood vessels which are considered to sacrifice during the procedure. Maki et al. [22] noted that ligation the LGA during gastrectomy could lead to liver ischaemia because of presence of the accessory or replaced left hepatic artery and Kim et al. [18] suggested preservation of the accessory left hepatic artery if the diameter of the LGA is equal or larger than $5 \mathrm{~mm}$.

Our study provides an insight into the anatomical patterns found in Poland. According to our finding, the prevalence of variations was significant, so we suggest applying 3D reconstruction method for evaluation of variation at least in patients who are candidate for mentioned surgical or interventional procedures. Further studies of this nature could lead to better technical planning of surgical procedures and avoiding inadvertent injuries that might compromise the results of medical procedures, leading to complications. Better knowledge of anatomical variations could ultimately contribute to reducing the rates of morbidity and mortality in endovascular procedures, abdominal surgeries, and transplantations, especially those of the liver and pancreas $[11,23,36]$.

\section{CONCLUSIONS}

Our study identified the variations in coeliac trunk anatomy in a sample of Polish population using Adachi's classification. Our results correlated well with studies in other populations. Adequate knowledge of these variations would be of great help to the interventional radiologist and hepatobiliary surgeon.

\section{REFERENCES}

1. Adachi B. Das Arteriensystem der Japaner. Vol. 2. Verlag der Kaiserlich-Japanischen Universitat zu Kyoto 1928.

2. Araujo Neto SA, Franca HA, de Mello Júnior CF, et al. Anatomical variations of the celiac trunk and hepatic arterial system: an analysis using multidetector computed tomography angiography. Radiol Bras. 2015; 48(6): 358-362, doi: 10.1590/01003984.2014.0100, indexed in Pubmed: 26811552.

3. Arifuzzaman M, Nasim $\mathrm{Na}$, Adel $\mathrm{H}$, et al. Anatomical variants of celiac trunk, hepatic and renal arteries in a population of developing country using multidetector computed tomography angiography. J Ayub Med Coll Abbottabad. 2017; 29(3): 450-454.

4. Brahmbhatt P, McKinney J, Litchfield J, et al. Mediastinal pancreatic pseudocyst with hemorrhage and left gastric artery pseudoaneurysm, managed with left gastric artery embolization and placement of percutaneous trans-hepatic pseudocyst drainage. Gastroenterol Rep (Oxf). 2016; 4(3): 241-245, doi: 10.1093/gastro/gou084, indexed in Pubmed: 25502760.

5. Brasil IR, de Araujo IF, Lima AA, et al. Computed tomography angiography study of variations of the celiac trunk and hepatic artery in 100 patients. Radiol Bras. 2018; 51(1): 32-36, doi: 10.1590/0100-3984.2016.0179, indexed in Pubmed: 29540943.

6. Cai L, Yeh BM, Westphalen AC, et al. Adult living donor liver imaging. Diagn Interv Radiol. 2016; 22(3): 207-214, doi: 10.5152/dir.2016.15323, indexed in Pubmed: 26912106.

7. Catalano OA, Singh $A H$, Uppot RN, et al. Vascular and biliary variants in the liver: implications for liver surgery. Radiographics. 2008; 28(2): 359-378, doi: 10.1148/ rg.282075099, indexed in Pubmed: 18349445.

8. Chen H, Yano R, Emura S, et al. Anatomic variation of the celiac trunk with special reference to hepatic artery patterns. Ann Anat. 2009; 191(4): 399-407, doi: 10.1016/j. aanat.2009.05.002, indexed in Pubmed: 19540742.

9. Cornelis van der Vlies $\mathrm{H}$, van Delden OM, Punt BJ, et al. Literature review of the role of ultrasound, computed tomography, and transcatheter arterial embolization for the treatment of traumatic splenic injuries. Cardiovasc Intervent Radiol. 2010; 33(6): 1079-1087, doi: 10.1007/ s00270-010-9943-6, indexed in Pubmed: 20668852.

10. Egorov VI, Yashina NI, Fedorov AV, et al. Celiaco-mesenterial arterial aberrations in patients undergoing extended pancreatic resections: correlation of CT angiography with findings at surgery. JOP. 2010; 11(4): 348-357, indexed in Pubmed: 20601809. 
11. Ekingen A, Tuncer MC, Ertuğrul Ö. Investigation of proper hepatic artery and gastroduodenal artery variations by multidetector computed tomography angiography method. Acta Chir Belg. 2020; 120(2): 102-115, doi: 10.1080/00015458.2019.1570744, indexed in Pubmed: 30714485.

12. Fink DM, Steele MM, Hollingsworth MA. The lymphatic system and pancreatic cancer. Cancer Lett. 2016; 381(1): 217-236, doi: 10.1016/j.canlet.2015.11.048, indexed in Pubmed: 26742462.

13. Ganeshan A, Upponi S, Hon Lq, et al. Hepatic arterial infusion of chemotherapy: the role of diagnostic and interventional radiology. Ann Oncol. 2008; 19(5): 847-851, doi: 10.1093/annonc/mdm528, indexed in Pubmed: 18029972.

14. lezzi R, Cotroneo AR, Giancristofaro D, et al. Multidetector-row CT angiographic imaging of the celiac trunk: anatomy and normal variants. Surg Radiol Anat. 2008; 30(4): 303-310, doi: 10.1007/s00276-008-0324-7, indexed in Pubmed: 18286222

15. Ishigami K, Zhang Y, Rayhill S, et al. Does variant hepatic artery anatomy in a liver transplant recipient increase the risk of hepatic artery complications after transplantation? Am J Roentgenol. 2004; 183(6): 1577-1584, doi: 10.2214/ ajr.183.6.01831577, indexed in Pubmed: 15547194.

16. Jain SK, Rajendran V, Jain MK, et al. Hemorrhagic pseudocyst of pancreas treated with coil embolization of gastroduodenal artery: a case report and review of literature. Case Rep Surg. 2015; 2015: 480605, doi: 10.1155/2015/480605, indexed in Pubmed: 26819796.

17. Juszczak A, Solewski B, Loukas $M$, et al. Unusual branching pattern of celiac trunk associated with supernumerary hepatic arteries and abnormal adrenal venous drainage case study and review of the literature. Folia Med Cracov. 2017; 57(3): 29-36, indexed in Pubmed: 29263452.

18. Kim J, Kim SuMi, Seo JE, et al. Should an aberrant left hepatic artery arising from the left gastric artery be preserved during laparoscopic gastrectomy for early gastric cancer treatment? J Gastric Cancer. 2016; 16(2): 72-77, doi: 10.5230/jgc.2016.16.2.72, indexed in Pubmed: 27433391.

19. Kim J, Shin JiH, Yoon HKi, et al. Endovascular intervention for management of pancreatitis-related bleeding: a retrospective analysis of thirty-seven patients at a single institution. Diagn Interv Radiol. 2015; 21(2): 140-147, doi: 10.5152/dir.2014.14085, indexed in Pubmed: 25616269.

20. Kimura S, Okazaki M, Higashihara $\mathrm{H}$, et al. Analysis of the origin of the right inferior phrenic artery in 178 patients with hepatocellular carcinoma treated by chemoembolization via the right inferior phrenic artery. Acta Radiol. 2007; 48(7): 728-733, doi: 10.1080/02841850701376334, indexed in Pubmed: 17729002

21. Kordzadeh A, Lorenzi B, Hanif MA, et al. Left gastric artery embolisation for the treatment of obesity: a systematic review. Obes Surg. 2018; 28(6): 1797-1802, doi: 10.1007/ s11695-018-3211-2, indexed in Pubmed: 29616467.

22. Maki H, Satodate $H$, Satou S, et al. Clinical evaluation of the aberrant left hepatic artery arising from the left gastric artery in esophagectomy. Surg Radiol Anat. 2018; 40(7): 749-756, doi: 10.1007/s00276-018-2022-4, indexed in Pubmed: 29651566

23. Marco-Clement I, Martinez-Barco A, Ahumada N, et al. Anatomical variations of the celiac trunk: cadaveric and radiological study. Surg Radiol Anat. 2016; 38(4): 501-510, doi: 10.1007/s00276-015-1542-4, indexed in Pubmed: 26267305.

24. Matsuki M, Tanikake M, Kani H, et al. Dual-phase 3D CT angiography during a single breath-hold using 16-MDCT: assessment of vascular anatomy before laparoscopic gastrectomy. Am J Roentgenol. 2006; 186(4): 1079-1085, doi: 10.2214/AJR.04.0733, indexed in Pubmed: 16554582.

25. Michels NA. Newer anatomy of the liver and its variant blood supply and collateral circulation. Am J Surg. 1966; 112(3): 337-347, doi: 10.1016/0002-9610(66)90201-7, indexed in Pubmed: 5917302.

26. Mu GC, Huang Y, Liu ZM, et al. Clinical research in individual information of celiac artery $\mathrm{CT}$ imaging and gastric cancer surgery. Clin Transl Oncol. 2013; 15(10): 774-779, doi: 10.1007/s12094-013-1002-8, indexed in Pubmed: 23359186.
27. Panagouli $E$, Venieratos $D$, Lolis $E$, et al. Variations in the anatomy of the celiac trunk: A systematic review and clinical implications. Ann Anat. 2013; 195(6): 501-511, doi: 10.1016/j.aanat.2013.06.003, indexed in Pubmed: 23972701.

28. Roma S, D'Amato D, Ranalli T, et al. Vascular anomalies of the celiac trunk and implications in treatment of HCC with TACE. Description of a case and review of the literature. Radiol Case Rep. 2019; 14(10): 1221-1227, doi: 10.1016/j. radcr.2019.07.011, indexed in Pubmed: 31428216.

29. Sankar KD, Bhanu PS, Susan PJ. Variant Anatomy of the Celiac Trunk and its Branches. Int J Morphol. 2011; 29(2): 581-584, doi: 10.4067/s0717-95022011000200047.

30. Song SY, Chung JW, Yin YHu, et al. Celiac axis and common hepatic artery variations in 5002 patients: systematic analysis with spiral CT and DSA. Radiology. 2010; 255(1): 278-288, doi: 10.1148/radiol.09090389, indexed in Pubmed: 20308464.

31. Sureka B, Mittal MK, Mittal A, et al. Variations of celiac axis, common hepatic artery and its branches in 600 patients. Indian J Radiol Imaging. 2013; 23(3): 223-233, doi: 10.4103/0971-3026.120273, indexed in Pubmed: 24347852

32. Takahashi EA, Takahashi N, Reisenauer CJ, et al. Body composition changes after left gastric artery embolization in overweight and obese individuals. Abdom Radiol (NY). 2019; 44(7): 2627-2631, doi: 10.1007/s00261-019-02002-6, indexed in Pubmed: 30949784.

33. Tandler J. über die Varietäten der Arteria coeliaca und deren Entwickelung. Beiträge und Referate zur Anatomie und Entwickelungsgeschichte. Anathefte. 1904; 25(2): 473-500, doi: 10.1007/bf02300762.

34. Tang W, Shi J, Kuang LQ, et al. Celiomesenteric trunk: New classification based on multidetector computed tomography angiographic findings and probable embryological mechanisms. World J Clin Cases. 2019; 7(23): 3980-3989, doi: 10.12998/wjcc.v7.i23.3980, indexed in Pubmed: 31832400.

35. Tokue H, Tokue A, Tsushima Y. Multidetector-row computed tomography for evaluating the branching angle of the celiac artery: a descriptive study. BMC Med Imaging. 2012 ; 12 : 36, doi: 10.1186/1471-2342-12-36, indexed in Pubmed: 23259976.

36. Ülger BV, Hatipoğlu ES, Ertuğrul Ö, et al. Variations in the vascular and biliary structures of the liver: a comprehensive anatomical study. Acta Chir Belg. 2018; 118(6): 354-371, doi: 10.1080/00015458.2018.1438565, indexed in Pubmed: 29433396.

37. von Haller A. Icones anatomicae in quibus aliquae partes corporis humani declineate proponuntur et arteriarum potissimum historia continetur. Vandenhoeck, Gottingen 1765.

38. Watson CJE, Harper SJF. Anatomical variation and its management in transplantation. Am J Transplant. 2015; 15(6): 1459-1471, doi: 10.1111/ajt.13310, indexed in Pubmed: 25981150.

39. Weiss CR, Abiola GO, Fischman AM, et al. Bariatric embolization of arteries for the treatment of obesity (BEAT obesity) trial: results at 1 year. Radiology. 2019; 291(3): 792-800, doi: 10.1148/radiol.2019182354, indexed in Pubmed: 30938624.

40. Winston $C B$, Lee NA, Jarnagin WR, et al. CT angiography for delineation of celiac and superior mesenteric artery variants in patients undergoing hepatobiliary and pancreatic surgery. Am J Roentgenol. 2007; 189(1): W13W19, doi: 10.2214/AJR.04.1374, indexed in Pubmed: 17579128 .

41. Winter TC, Nghiem HV, Freeny PC, et al. Hepatic arterial anatomy: demonstration of normal supply and vascular variants with three-dimensional CT angiography. Radiographics. 1995; 15(4): 771-780, doi: 10.1148/radiographics.15.4.7569128, indexed in Pubmed: 7569128.

42. Zaki SM, Abdelmaksoud AHK, Khaled BEA, et al. Anatomical variations of hepatic artery using the multidetector computed tomography angiography. Folia Morphol. 2020; 79(2): 247-254, doi: 10.5603/FM.a2019.0090, indexed in Pubmed: 31436302. 